\title{
Imagem fílmica: um encontro que nos convoca a pensar
}

Filmic image: an encounter that convokes our thinking

\author{
Vivien Kelling Cardonetti ${ }^{i}$ \\ Marilda Oliveira de Oliveiraii \\ Universidade Federal de Santa Maria
}

\section{Resumo}

Este texto intenciona movimentar diferentes fluxos de pensamentos a partir das inquietações que dispararam de um encontro fílmico. Em vista das experiências em assistir ao filme 'A Árvore da Vida' (2011) em dois cenários distintos (em um contexto distante do âmbito da academia e o outro com os acadêmicos da Graduação em Artes Visuais da Universidade Federal de Santa Maria - RS), buscou-se explorar o atravessamento da imagem fílmica selecionada, das narrativas produzidas nos diários pelos envolvidos na investigação e dos conceitos operados na pesquisa, especialmente os conceitos de imagem-movimento e imagem-tempo (DELEUZE, 1983; 1990; 2010). As problematizações suscitadas a partir deste cruzamento tiveram a potência de afetar e inquietar, possibilitando a produção de diferentes arranjos e tessituras em relação às imagens fílmicas e à experiência educativa.

Palavras-chave: pensamento, imagem fílmica, imagem-movimento, imagem-tempo, experiência educativa.

\section{Abstract}

The aim in this text is to move different fluxes of thought through some concerns triggered by a filmic encounter. Through experiences of watching the movie "The Tree of Life" (2011) in two different scenarios (a context apart from the academy and another with undergraduate students of Visual Arts at Federal University of Santa Maria-RS), we aimed at exploring the crossing of the filmic image being explored, narratives produced in diaries by the participants involved in this investigation, and the concepts articulated in this research, especially those of movement-image and time-image (DELEUZE, 1983; 1990; 2010). Problematizations raised in this crossing has the potency to affect and disquiet, allowing the production of different arrangements and textures in relation to filmic images and the educative experience.

Keywords: though, filmic image, movement-image, time-image, educative experience.

Revista Digital do LAV - Santa Maria - vol. 10, n. 2, p. 39 - 38 - mai./ago. 2017 ISSN 1983 - 7348 http://dx.doi.org/10.5902/1983734828786 
A penumbra do cinema não deixa transparecer os sentimentos que me assaltam no momento... Irritação, desconforto e constrangimento são emoções que passam a me acompanhar. Não tenho certeza se o incômodo estava relacionado somente por visualizar as pessoas se levantarem das cadeiras e irem embora, ou se era por eu não ter coragem suficiente de fazer o mesmo. Além do transtorno que o movimento da plateia causava, não escondiam sua decepção, pois desejavam deixar claro através de comentários o porquê estavam se retirando.

Imagens ilógicas, discordantes e desconexas estavam todas na tela. Imagens que deixaram de fazer parte do seu lugar no tempo crônico, mas que agora estavam ali, errantes, suspensas no ar. A linearidade e a totalidade foram abaladas. Sim, são imagens vivas em um universo acentrado!

Ao compor com diferentes cenas descritas por mim de 'desarmônicas', observo que suas bordas não se ajustam, mas ressoam, como se um tênue fio transpassasse entre elas. Visualizo também alguns fios soltos e, talvez por isso, outros fios se sentem encorajados e passam a fazer parte deste emaranhado de fios. Por vezes, surgem elos frouxos, lacunas e hiatos entre as imagens, possibilitando a dispersão e a presença do acaso. Desponta outro tipo de reencadeamento entre as imagens, a presença do 'interstício' se faz presente.

Constato que o protagonista do filme também é um espectador, pois desconhece o que vai acontecer, não é mais o agente da situação. Essa sensação me faz sentir mais próxima do ator em cena, colocando-me numa relação de empatia com o personagem do filme. Sentir-me outro sem ser o outro.

No filme, a congruência da organização e da sequência entre a ação e a reação passa a ruir, a ponto de não existirem mais os momentos fortes e fracos delimitados, qualquer cena pode ser alastrada em horizontes mais dilatados e múltiplos, de acordo com as contingências do momento. Isso passa a me desconcertar, pois os acontecimentos estão ao sabor do que não pode ser auspiciado. Dessa forma, o movimento deixa de acatar seu eixo central, e o tempo, por sua vez, também sai dos eixos. Ao assistir ao filme 'A 
Árvore da Vida', inaugura-se para mim, pela primeira vez, uma relação diferente com a imagem fílmica...

(Fragmentos do diário pessoal da primeira autora, agosto de 2012).

O filme acabou e a pergunta que fica é: Que filme é esse? Sobre o que trata, afinal? Sobre religião? Sobre Deus? Sobre os hábitos cotidianos de uma família? Sobre as divergências de posicionamento frente ao modo como vemos/vivemos a vida? Sobre como educar os filhos? Sim, sobre tudo isso, mas principalmente trata sobre o 'silêncio'. As perguntas que o silêncio nos faz. Por que eu? Por que isso aconteceu comigo? De onde vem essa dor? Porque calamos quando queremos dizer alguma coisa? Porque nos arrependemos por não ter dito? Apegamo-nos a questões tão pequenas que, quando realmente nos deparamos com algo maior que nossas ninharias, paralisamos. Foi assim que me senti quando o filme acabou e pensei: E agora, como será a discussão sobre esse filme? Que relações podemos estabelecer com a docência? Que interlocuções são possíveis? Como os estudantes perceberam o filme?

A discussão com os acadêmicos girou em torno das 'nossas crenças'. Em que acreditamos? Como construímos nossas verdades? O que fazemos em nome delas? Para mim, essa não era a questão principal do filme, mas acompanhei a discussão e o que mais me chamou a atenção foram algumas conclusões lançadas naquele encontro: As nossas verdades nos impedem de amar. As nossas crenças nos sufocam ao ponto de nos cegarem. Quando acreditamos muito em alguma coisa não conseguimos perceber 0 que acontece a nossa volta. O que nos impede de mudar o curso da nossa vida são as amarras que nós mesmos nos colocamos.

Assim, para mim, o que ficou desse encontro foi o impacto, não com o filme, mas com a discussão com os estudantes que me mostraram uma outra forma de ver o mesmo, pois em nada aproximou-se com aquilo que pensei, anotei e elaborei.

Hoje, quando penso nesse encontro e tento elaborar o que ficou da experiência com 'A árvore da vida' sinto uma sensação de conforto

Revista Digital do LAV - Santa Maria - vol. 10, n. 2, p. 39 - 55 - mai./ago. 2017 ISSN 1983 - 7348 http://dx.doi.org/10.5902/1983734828786 
e aprendizagem. Já não lembro das imagens fílmicas, mas dos rostos dos estudantes elaborando suas histórias sobre o que viram. Acho que é um pouco disso que tentei fazer aqui.

(Fragmentos do diário pessoal da segunda autora, junho de 2015).

Neste artigo, buscamos explorar o encontro de alguns fragmentos dos nossos diários pessoais e como o cruzamento dessas narrativas passaram a ser disparadoras do pensar, tendo a potência de nos arremessar a uma paisagem problematizadora. Duas experiências que ocorreram em locais e momentos distintos, mas que de certa forma passaram a ressoar e a coexistir nesta escrita. Um dos encontros aconteceu no cinema, em uma circunstância distante das atividades acadêmicas, e o outro ocorreu em um trabalho desenvolvido com os estudantes da Graduação em Artes Visuais da Universidade Federal de Santa Maria - RS, nas disciplinas de Estágio Supervisionado III e IV (OLIVEIRA, 2014).

A relação que se se estabeleceu com o filme 'A Árvore da Vida' (2011) e com o cenário circunstancial desses dois encontros, possibilitou a produção de diferentes disposições e tessituras. Passamos a dar atenção ao quanto esses dois momentos nos forçaram e violentaram a pensar a imagem fílmica, a experiência educativa e a vida.

Por apresentar outro tipo de imagem, foi possível estabelecer inusitadas relações com o filme, facultando o tensionamento favorável para pensar aquilo que não é auspiciado e brindando-nos com a oportunidade de ensaiar uma paisagem ampla de possibilidades e sentidos. O tensionamento com aquilo que é adverso e incompatível, permitiu que o pensamento fosse coagido a pensar outras coisas, interrompendo a apatia e a paralisia que por vezes nos aprisiona.

Nesta direção, com a intenção de atender aos anseios da investigação, optamos por uma pesquisa de cunho narrativo, presentificada nos fragmentos dos nossos diários textuais. Zabalza coloca que o diário é visto como um local de intercâmbio, onde as pessoas, ao narrar, vão "travando uma 'conversa' consigo mesmo[as] e com os virtuais destinatários do relato" (2004, p. 49, grifo do autor). Nessa investigação, o diário passou a ser um espaço narrativo dos nossos pensamentos, expressando em versões textuais as impressões que tivemos do encontro fílmico e das experiências educativas vivenciadas a partir do filme, problematizando-as. O diário possibilitou uma visão panorâmica dos sentidos produzidos nestas experiências, apresentando as próprias redes de afetos que potencializaram ou não o pensar.

A partir das paisagens singulares do encontro vivenciado, procuramos explorar 0 atravessamento da imagem fílmica selecionada, das narrativas produzidas nos diários e dos conceitos operados na pesquisa, especialmente os conceitos de imagem-movimento

Revista Digital do LAV - Santa Maria - vol. 10, n. 2, p. 39 - 55 - mai./ago. 2017 ISSN 1983 - 7348 http://dx.doi.org/10.5902/1983734828786 
e imagem-tempo (DELEUZE, 1983; 1990; 2010). Esses desdobramentos tiveram importância, pois eles passaram a se conectar e se complementar, contribuindo para a produção dessa escrita.

\section{O que nos impele a pensar}

O pensamento não pode ser confundido com o evento da recognição. A recognição não necessita de esforço, o trabalho é de associação e de reconhecimento, pois se reencontra sempre com o habitual e com o familiar. Além de se unir ao sujeito ou ao objeto correspondente, conecta-se também com valores vigentes e universais instituídos, por isso passa a ser uma operação redundante. O pensamento, por sua vez, é involuntário, necessita ser coagido e violentado. Conta com as circunstâncias do instante e com aquilo que o impulsiona a pensar. Está aberto ao incomum, ao intolerável, ao extraordinário.

Os encontros fortuitos lidam com a imprevisibilidade, com o não conhecido, com aquilo que não pode ser antecipado, causando o estranhamento. E é justamente esse encontro surpreendente, movediço e oscilante que assegura a premência daquilo que é pensado. Quando estamos à mercê do inesperado em um encontro, distanciamo-nos da realidade costumeira e da referência cognitiva que nos causam segurança e é esta atmosfera acontecimental que assegura a necessidade do que pensamos.

Deleuze assinala que é notório que os "atos de recognição existem e ocupam grande parte de nossa vida cotidiana: é uma mesa, é uma maçã, (...). Mas quem pode acreditar que o destino do pensamento se joga aí e que pensemos quando reconhecemos?" (2006b, p. 197). Pensar não significa exercitar movimentos mecânicos de reconhecimento e de combinação com o corriqueiro ou com algo preestabelecido, pensar está relacionado com a criação.

Ao criar, movimentamos a produção de diferenças, e não de similaridades, uma vez que passamos a pensar o que ainda não existe, em vez de nos contentarmos com o que já é dado e consolidado. É por isso que ao pensar se abrem possibilidades de inventar diferentes perspectivas de vida para o mundo em que vivemos, pois, "o melhor dos mundos é não aquele que reproduz o eterno, mas aquele em que se produz o novo, aquele que tem uma capacidade de novidade, de criatividade" (DELEUZE, 2007, p. 136). Nesse sentido, pensar pressupõe se desprender de dogmas, abrindo mão da necessidade de um roteiro que sirva de apoio e que garanta as certezas fáceis. Os pensamentos mais impetuosos são os que duvidam das verdades impostas e levam em consideração o falso e a fabulação.

Na experiência educativa, com a intenção de auxiliar a leitura de um texto, a visualização de uma imagem ou de um filme, passamos, por vezes, a direcionar os estudantes a

Revista Digital do LAV - Santa Maria - vol. 10, n. 2, p. 39 - 55 - mai./ago. 2017 ISSN 1983 - 7348 http://dx.doi.org/10.5902/1983734828786 
fazerem associações e interpretações endossadas por verdades que acreditamos serem universais. No entanto, ninguém "poderia, com regra alguma, facilitar a leitura, consistindo esta num ato criador que não admite suplentes nem colaboradores" (DELEUZE, 2006a, p. 90). Não que as interpretações concebidas ou reproduzidas pelos professores não possam ser coerentes e válidas, mas são apenas mais uma das verdades possíveis.

Dessa forma, para produzir movimentos que vão além de uma recognição, ou que não se acomodem em uma recognição, faz-se necessário problematizar o que nos é dado como verdade e se abrir a inusitados fluxos de forças que nos impulsionem a inventar outras construções de sentido. Ao pensar, não estamos reconhecendo ou conhecendo a verdade, e sim produzindo-a, pois, a verdade é sempre uma verdade do seu tempo.

O cinema para Deleuze, principalmente o cinema moderno, foi um dos intercessores que o instigou a pensar e a produzir sua filosofia. Deleuze revela que "a criação são os intercessores. Sem eles não há obra. Podem ser pessoas (...) mas também coisas, plantas, até animais, (...). Fictícios ou reais, animados ou inanimados" (2010, p. 160). Vasconcellos, a partir dos estudos em Deleuze, expressa que "o intercessor é qualquer encontro que faz o pensamento sair de sua imobilidade natural, de seu estupor. Sem os intercessores não há criação. Sem eles não há pensamento" (VASCONCELLOS, 2006, p. 7).

Apostamos, também, na ideia de que as imagens fílmicas possam ser disparadoras do pensar, arremessando-nos a uma paisagem problematizadora. Não a imagem em si, mas a relação que se estabelece com a imagem e com as implicações do cenário circunstancial de cada encontro.

A imagem é relação e por isso não há como pensar a imagem individualmente, pois ela é aliança. É no emaranhado dos liames produzidos com a imagem fílmica que, talvez, venhamos a ser incitados e contagiados por signos que se encontram neste potente campo de confluências em que estamos enredados.

O desafio talvez esteja em se deixar afetar não por vozes conhecidas, "mas sim a voz de um outro, uma voz real, profunda, que incomoda" (BLANCHOT, 1997, p. 297) e que provoca o pensar. Que faz duvidar as certezas e que abala as verdades, que propicia a problematização de valores há muito tempo estagnados, ocasionando o movimento de transgressão e de renovação.

\section{Disparadores do pensar: encontros com o filme 'A árvore da vida'}

Ao sermos atravessadas e capturadas pelos dois encontros com o filme 'A árvore da vida' (2011), narrados nos diários pessoais, sentimos a necessidade de nos aproximar cada

Revista Digital do LAV - Santa Maria - vol. 10, n. 2, p. 39 - 55 - mai./ago. 2017 ISSN 1983 - 7348 http://dx.doi.org/10.5902/1983734828786 
vez mais de outros intercessores que estudaram e estudam o cinema. As duas obras de Gilles Deleuze sobre a arte cinematográfica foram determinantes para que viéssemos a pensar as imagens fílmicas de uma forma ampliada.

Deleuze dedicou ao cinema dois volumes: Cinema 1 - Imagem-movimento (1987) e Cinema 2 - Imagem-tempo (1990). Ambos foram importantes para ajudá-lo a pensar e problematizar esta arte e também para criar conceitos filosóficos. Nesses exemplares, dois conceitos principais são trabalhados: o movimento e o tempo.

Em busca de dar conta das exigências que os fragmentos narrados nos diários dispararam, passamos a nos debruçar mais demoradamente em alguns conceitos dessas duas obras: imagem-movimento e imagem-tempo. Esta colocação reafirma a implicação da teoria e da prática, pois, devido à premência do momento, sente-se ora a necessidade de buscar conceitos para compreender o que está acontecendo na investigação, ora a teoria estudada faz com que o nosso olhar fique mais atento e se direcione para determinadas coisas que, talvez, ficariam imperceptíveis se não houvesse o chamamento da teoria. Teoria e prática vão se atualizando intensamente no decorrer da pesquisa.

A escolha em explorar o filme 'A Árvore da Vida' (2011), produzido nos Estados Unidos e com direção de Terrence Malick, partiu da intenção de investir em imagens que produzissem diferenças e não similaridades, abrindo mão das relações de reconhecimento e de associação.

As imagens fílmicas que nos incitam a sair da posição cômoda de reconhecimento em que muitas vezes nos encontramos, que nos incomodam pelas lacunas e vazios produzidos em cena, que nos tocam a ponto de causar incômodos e inquietações, são as que mais nos afetam e nos levam a ter sensações e experiências estrangeiras e insólitas.

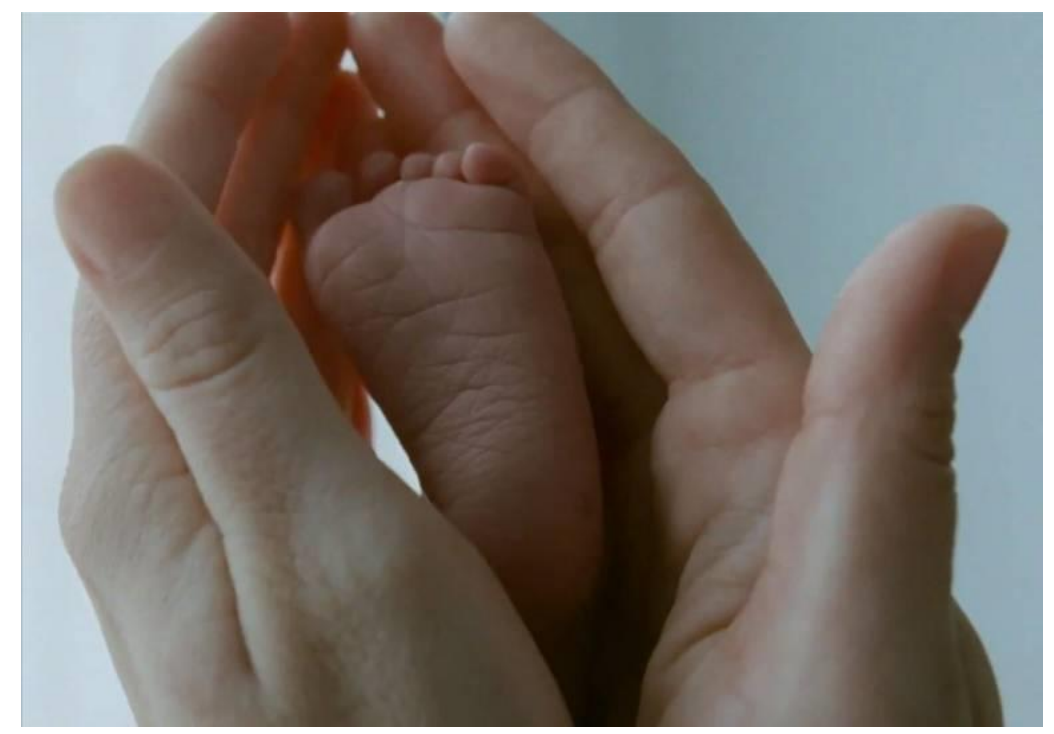

Figura 1: Imagem do filme 'A Árvore da Vida' (2011).

Fonte: <http://www.cafecomfilme.com.br/criticas/critica-do-filme-a-arvore-da-vida>.

Revista Digital do LAV - Santa Maria - vol. 10, n. 2, p. 39 - 55 - mai./ago. 2017 ISSN 1983 - 7348 http://dx.doi.org/10.5902/1983734828786 
O filme 'A Árvore da Vida' (2011), ganhador da Palma de Ouro do Festival de Cannes, traz no elenco Brad Pitt, Sean Penn, Jessica Chastain e Hunter McCracken. Para alguns críticos o gênero do filme é classificado como drama, para outros como um documentário fotográfico. Entretanto, mais importante do que saber em que categorização o filme pertence, é se deixar embriagar pela poesia das palavras e pela intensidade das imagens apresentadas.

\section{Imagem-movimento e imagem-tempo}

Deleuze (1990) discorre sobre o fato de que, no cinema clássico, o cinema se reduz à imagem-movimento. Por acolher um esquema sensório-motor, o tempo se submete ao movimento, ou seja, ocorre a sujeição do tempo ao movimento, é o automovimento da imagem.

No cinema moderno, a imagem cinematográfica se converte em uma imagem-tempo quando o movimento passa a se sujeitar ao tempo, é a autotemporalização da imagem. O tempo é visto na sua forma pura, as situações são caracterizadas pelos vazios e pelas descontinuidades, tornando-se dispersivas. São realizadas por cortes incongruentes e não mais por relações de atração e associação das imagens, como acontecia na imagemmovimento.

Deleuze esclarece que "as imagens-tempo não significam de modo algum o antes e o depois, a sucessão. (...). A imagem-tempo não se confunde com o que se passa no tempo, são novas formas de coexistência, de colocação em série, de transformação" (2010, p. 158). Passado, presente e futuro ocupam o mesmo espaço no tempo, abolindo a progressão e a linearidade entre os três tempos. A imagem-tempo, por não mais responder aos estímulos sensório-motores, permite-se arrastar pela 'visão' dos acontecimentos.

No regime temporal da imagem-tempo, deixa de existir o tempo cronológico que pode ocasionalmente ser importunado por movimentos incomuns e passa a haver um tempo crônico, não linear e progressivo, que gera movimentos inevitavelmente inusitados e imprevisíveis. As imagens fílmicas, neste regime, são arremessadas a outras imagens, potencializando a dispersão. Não se tem como prever quais imagens estarão em jogo, que reações serão realizadas, o que os signos farão evocar e o que se produzirá de tudo isso. É justamente esse cenário incerto e inesperado que possibilita encontros fílmicos sempre singulares e em vias de acontecer.

O cinema apresenta, na imagem-tempo, uma diferente relação com o pensamento, pois ocorre "a supressão de um todo ou de uma totalização das imagens, em favor de um fora que se insere entre elas" (DELEZE, 1990, p. 226). Possibilita-se, dessa forma, pensar em

Revista Digital do LAV - Santa Maria - vol. 10, n. 2, p. 39 - 55 - mai./ago. 2017 ISSN 1983 - 7348 http://dx.doi.org/10.5902/1983734828786 
diferentes alianças, pois o tempo não é mais regido pelo verbo 'ser', e sim pela conjunção ' $e$ ', não mais como 'ser' e sim como 'entre', pois atua nos vacúolos das imagens, e não mais com a associação de imagens. A imagem recebe alforria de seu limitado decreto representativo, recognitivo, ilustrativo e demonstrativo.

A partir do que foi exposto, podemos perceber que o filme 'A Árvore da Vida' (2011) traz em cena a imagem ótica e sonora pura, elemento primordial da imagem-tempo. Essa imagem que nos incomoda, que nos escapa a todo momento e que nos tira dos eixos, é a que também nos provoca a ter outras experiências com as imagens. Semelhante incômodo, desconforto e perplexidade foi perceptível na escrita dos diários que anuncia este texto, pois em algumas situações o estranhamento foi tanto que levou à rejeição, a ponto de certas pessoas se retirarem do cinema antes do filme terminar. Em outras, na experiência com os acadêmicos, foi possível perceber o quanto as discussões em relação a um mesmo filme se mostraram múltiplas, distanciando-se da possibilidade de qualquer consenso.

Fazer funcionar áreas que se acham paralisadas e definidas em nós causa-nos, por vezes, dor e sofrimento. É desafiador se deixar afetar pela visão dos acontecimentos, pelos movimentos imprevisíveis, pelos hiatos, pelos cortes discordantes, pelos percursos desviantes e pelo campo multifacetado que uma imagem-tempo pode incitar.

\section{As inesgotáveis nuances da imagem}

Deleuze (1990, p. 61) evidencia que as imagens óticas puras "sempre elevam a coisa a uma singularidade essencial, e descrevem o inesgotável, remetendo sem fim a outras descrições". As descrições fazem explorar os inexauríveis matizes e facetas da imagem, estas se fixam em algo, demorando-se a ponto de investigar outras perspectivas da mesma coisa.

A imagem sensório-motora apresenta um modo de encadeamento diferente da imagem ótica e sonora pura, pois na primeira ocorre o encadeamento de uma imagem-percepção a uma imagem-ação, acatando uma triagem conveniente. Passa-se a "associar à coisa muitas outras coisas que se parecem com ela no mesmo plano, na medida em que todas suscitam movimentos semelhantes" (DELEUZE, 1990, p. 61).

$\mathrm{Na}$ segunda, os encadeamentos entre as imagens se tornam enfraquecidos, pois as linhas que unem os acontecimentos são rompidas a todo momento. A estrutura que assegurava a sequência e a sucessão das imagens passa a ruir. Não ocorre prolongamento em movimento, pois há uma relação constante com o imprevisível, com o que acontece no 'entre', com o que ocorre nas lacunas e nos hiatos das imagens.

Revista Digital do LAV - Santa Maria - vol. 10, n. 2, p. 39 - 55 - mai./ago. 2017 ISSN 1983 - 7348 http://dx.doi.org/10.5902/1983734828786 
A rarefação das imagens que o filme 'A Árvore da Vida' (2011) apresenta, convida e encoraja que outras relações possam ser realizadas e diferentes descrições aconteçam, reportando-se a outras imagens. Passa-se a vislumbrar no 'entre' das cenas pequenos microrganismos e atividades celulares, imagens oceânicas, atômicas, vulcânicas, desérticas e astronômicas. As imagens passam a estar sujeitas a permanentes interrupções e escapes, e é esse desencadeamento que leva à dissipação e à criação de múltiplas possibilidades, distanciando-se do previsível, do trivial, do lugar-comum, da monotonia, da matriz.

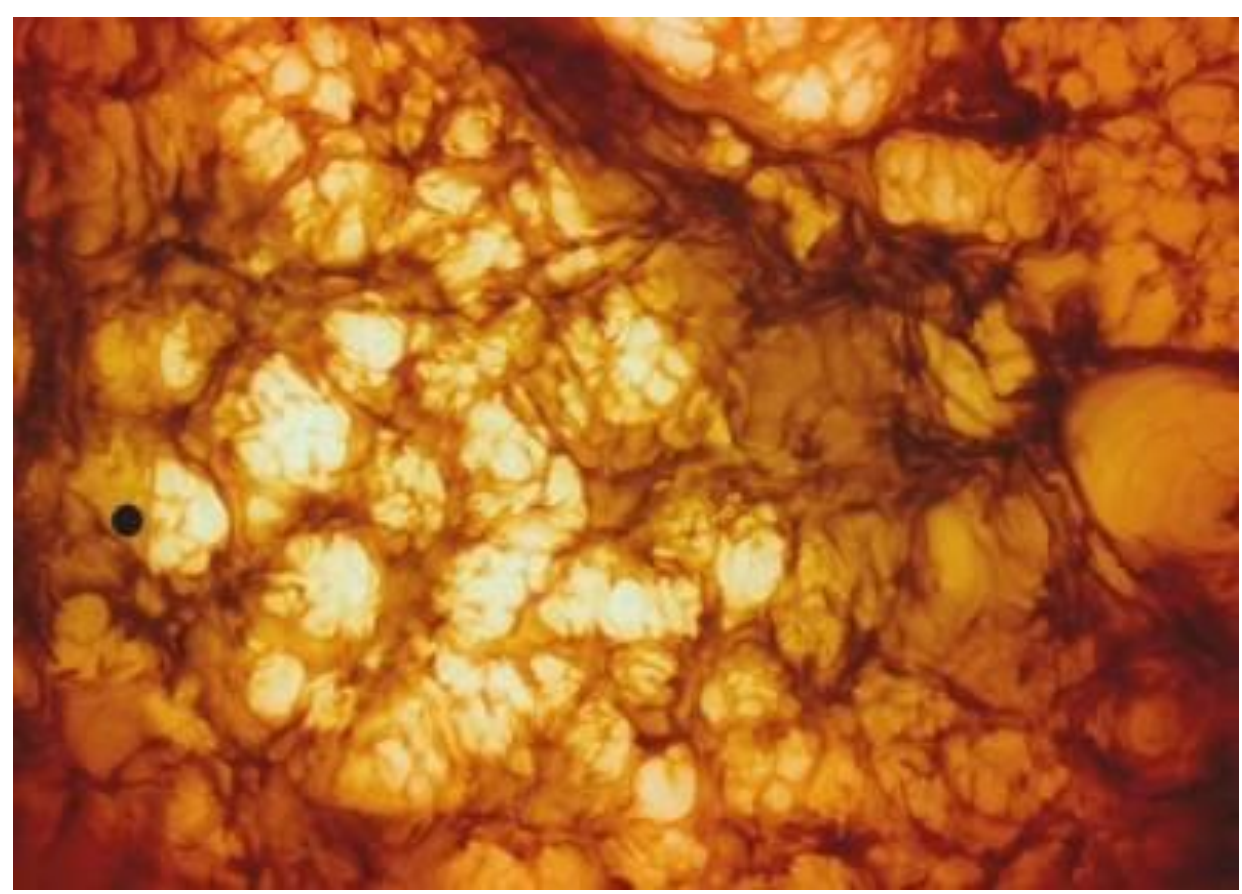

Figura 2: Imagem do filme 'A Árvore da Vida' (2011).

Fonte: $\quad<$ http://falaleonardo.com/2011/08/08/a-arvore-da-vida-e-filme-com-completaausencia-de-texto/>

Em vez de serem interpretadas, essas imagens nos oferecem singulares experienciações, pois elas ressoam em múltiplas direções e sentidos, convidando-nos a engendrar diferentes vinculações. Ao tirar proveito de sua faculdade plural, essas imagens são impelidas a outras imagens, diversamente do sentido representativo, em que as imagens voltam para si mesmas. Esta valência múltipla contribui para que o observador concorra para sua profusão e dispersão. Isto nos faz pensar que "uma imagem nunca está só. 0 que conta é a relação entre as imagens" (DELEUZE, 2010, p. 71-72).

É nesta relação que a problematização do pensamento se faz presente, pois nas descrições sobressaem outros matizes, propiciando diálogos com liames por vezes desconhecidos e instigantes. E, retornando mais uma vez aos diários da pesquisa,

Revista Digital do LAV - Santa Maria - vol. 10, n. 2, p. 39 - 55 - mai./ago. 2017 ISSN 1983 - 7348 http://dx.doi.org/10.5902/1983734828786 
fazendo-nos ver o que nos parecia impossível perceber, a ponto de nos questionarmos se havíamos assistido ao mesmo filme.

As descrições, por se encontrarem deslocadas, são questionadas e substituídas, propelindo a outras conexões. A provisoriedade passa a ser uma característica das imagens-tempo, pois elas estarão sempre em deslocamento, de acordo com as exigências e as forças em cena.

\section{O cinema de vidência}

Nas imagens-tempo apresentadas no filme, os personagens não reagem ao que thes acontece, eles se encontram em estado de errância. Os personagens são indiferentes ou são tomados de surpresa pelos acontecimentos, pois não agem e nem reagem imediatamente. Eles desejam ver o que acontece antes de tomar qualquer iniciativa.

Este cinema é considerado como o cinema de 'vidência', pois os personagens passam a ser observadores das situações. Atuam por afetos que excedem a cena dramática do filme e não por forças táteis (DELEUZE, 1990). Os acontecimentos, neste regime, são narrados de forma casual, pois estão à mercê do imprevisto, do inusitado. Não existe mais um espaço específico, os espaços são lacunares e não estão mais associados, caracterizando-se, desta forma, a perambulação e a dispersão. Os personagens do filme - Sr. O'Brien e Sra. O'Brien, Jack criança e adulto - variam, pois ora eles se apresentam como protagonistas, ora como coadjuvantes.

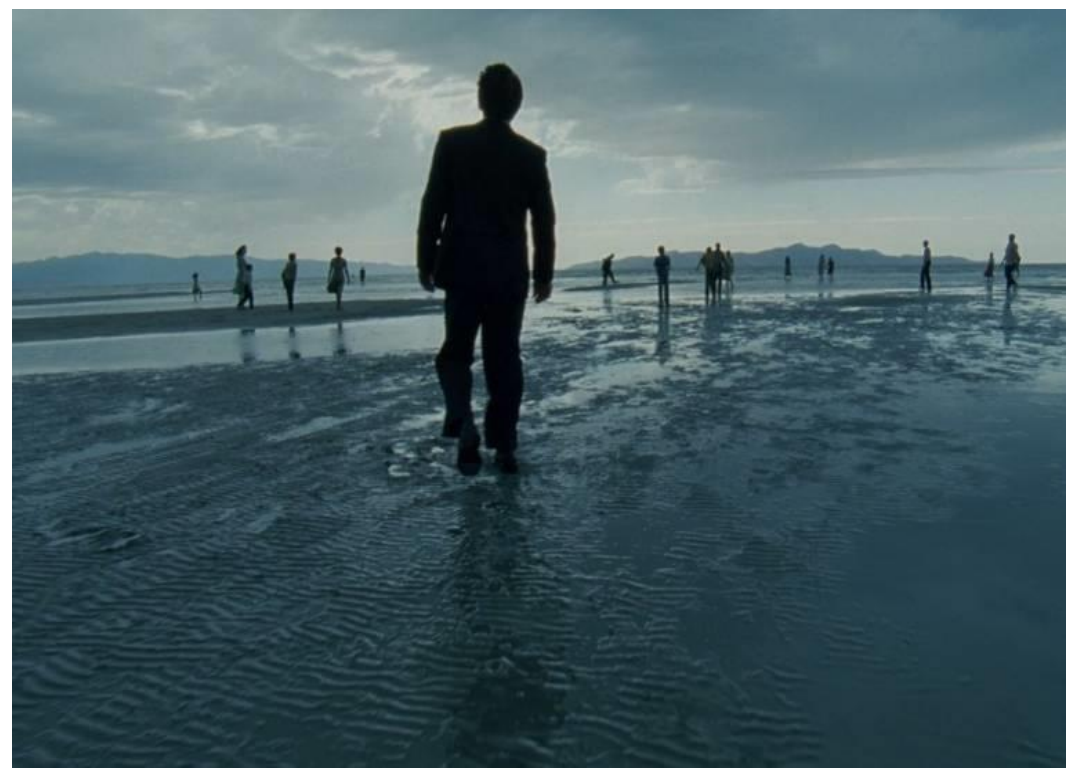

Figura 3: Imagem do filme 'A Árvore da Vida' (2011).

Fonte:

<http://obviousmag.org/archives/2012/06/terrence malick e o cinema existencial.htm I>.

Revista Digital do LAV - Santa Maria - vol. 10, n. 2, p. 39 - 55 - mai./ago. 2017 ISSN 1983 - 7348 http://dx.doi.org/10.5902/1983734828786 
Ao se trabalhar com imagens óticas e sonoras puras, o cinema de ação passa a ser substituído pelo cinema de vidência, ocorrendo a interrupção do esquema sensóriomotor, a suspensão do prolongamento da ação. A imagem-movimento, aprisionada ao vínculo sensório-motor, oferece apenas uma imagem indireta do tempo, entretanto a imagem ótica e sonora pura oferece uma imagem-tempo que propicia ao olho obter uma função de vidência, uma posição visionária.

A vidência do olho propicia que a coisa apreendida se alastre em circuitos cada vez mais amplos, conectando-se com as imagens-lembrança que ela mesma fomenta. É possível perceber que o filme trafega nesses lençóis de passado, entre a vida atual de Jack e a vida de Jack criança. As imagens-lembrança, por estarem relacionadas com os lençóis de passado, entram em diálogo com "algo real e imaginário, físico e mental, objetivo e subjetivo, descrição e narração, atual e virtual" (DELEUZE, 1990, p. 61, grifo do autor).

\section{O movimento silencioso da imagem}

O encontro com o filme 'A Árvore da Vida' (2011) nos oferece inúmeras imagens silenciosas, com a intensidade para nos arrebatar da posição inerte e tranquila em que por vezes nos colocamos. Elas nos instigam a estabelecer relações, a deambular, fazendo com que a agitação tácita da imagem tenha a potência de ressoar, alastrando-se ao infinito.

As imagens silenciosas podem ser potentes para disparar o pensar, pois oferecem 0 silêncio necessário para que possamos nos ouvir. É nesse sentido que, no silêncio impactante do final do filme, um hiato se faz presente e isto parece nos inquietar. Por oferecer tantos pontos de interrogação e apresentar um final incerto, sem respostas a tantos 'porquês' lançados durante o filme, sem um 'fechamento', sem um 'ponto final', isso causa incômodo e nos tira dos eixos.

Paradoxalmente, são essas mesmas sensações de desconforto que também nos capturam e nos fazem pensar na experiência educativa, movendo-nos a problematizar algumas questões: por que este sentimento em que tudo necessita ter um encerramento? Por que precisamos chegar a conclusões semelhantes e entender a mesma coisa? Por que precisamos deixar tudo tão amarrado, sem espaços para outros finais, ou melhor, outros 'meios' e outras possibilidades? Por que na experiência educativa necessitamos tudo explicar e arrematar? Por que precisamos fazer o 'fechamento' de nossas aulas, como se elas necessitassem de uma conclusão? Não poderíamos deixar ecoando problemas, em vez de encerrar com respostas?

Revista Digital do LAV - Santa Maria - vol. 10, n. 2, p. 39 - 55 - mai./ago. 2017 ISSN 1983 - 7348 http://dx.doi.org/10.5902/1983734828786 
A experiência com o filme nos oferece, ao final, uma lacuna não preenchida, uma impressão de algo não terminado, deixando uma abertura e uma expectativa de algo por vir. É uma sensação de algo mais, de reticências, instigando-nos a pensar nesta outra possibilidade de temporalidade, como algo intenso e que dura. A duração aparenta estar naquilo que uma imagem-tempo faz brotar em nós e no desassossego a que ela nos lança.

\section{Atravessamentos que nos instigam a problematizar a relação com a imagem fílmica}

No território de confluência do filme investigado, buscamos, neste texto, apostar na problematização e no estabelecimento de relações com os conceitos de imagemmovimento e de imagem-tempo. A intenção não foi fazer um comparativo excludente entre os dois tipos de imagens, colocando que uma tem mais importância que a outra, o intuito foi mostrar o quanto essas imagens operam nos filmes, suas implicações e também de que forma elas instigam à nossa maneira de pensar.

Dessa forma, intentamos com as imagens-tempo do filme 'A Árvore da Vida' (2011) incitar o pensamento, pois é no interstício, no 'entre' dessas imagens que muitas coisas podem ser cruzadas e construídas. É neste espaço aberto das imagens que alianças são concebidas e que inesperadas construções de sentido são invencionadas, fazendo-nos compreender que a maneira de nos relacionar com a imagem não depende somente do olhar do observador, tampouco do que é visualizado, e sim daquilo que é possível de ser produzido.

Ao trabalhar e explorar o filme, foi possível incitar a pensar possíveis desdobramentos que não se parecessem com o mesmo, que não fossem substituídos pela metáfora, que não desencadeassem movimentos semelhantes, caindo em um prolongamento do que já existe. O desafio foi pensar em possibilidades provisórias e substituíveis, sempre em devir.

Investir na relação com a imagem, sem a preocupação em corresponder, equivaler, interpretar e reproduzir, passa a ser um esforço diário, pois como Deleuze (1990, p. 31) explica:

nós não percebemos a coisa ou a imagem inteira, percebemos sempre menos, percebemos apenas o que estamos interessados em perceber, ou melhor, o que temos interesse em perceber, devido a nossos interesses econômicos, nossas crenças 
ideológicas, nossas exigências psicológicas. Portanto, comumente, percebemos apenas clichês.

A comodidade dos lugares-comuns faz com que venhamos a repetir o que é previsível, o que é corriqueiro e trivial. Converter as disposições sensório-motoras em disposições óticas e sonoras puras requer a criação de maneiras diferenciadas de entendimento, trazendo para o debate as imagens chavões que nos fazem repetir o mesmo e as metáforas que fazem resultar imagens concordantes com o que já existe.

Talvez a provocação maior esteja em problematizar essas imagens que nos são familiar e nos dão segurança, buscando trazer para a discussão uma nova imagem do pensamento, ou melhor, um pensamento sem imagem. "Um pensamento sem imagem é aquele que não obedece a uma imagem prévia do que seja pensar, isto é, a um modelo prévio que orienta e formata, que determinaria de antemão o que significa pensar" (PELBART, 2010, p. 28-29).

Ao se deixar violentar pelos signos que o diálogo entre a imagem fílmica selecionada, os conceitos investigados e a experiência educativa provocam, oportunizou-se diferentes relações e um alastramento de possibilidades em circuitos cada vez mais amplos. As ressonâncias que foram dissipadas podem ser vistas "como aventuras singulares do pensamento às quais a existência múltipla do cinema deu vida" (RANCIÈRE, 2012, p. 17) e têm a propriedade de se renovar a cada novo encontro, pois as relações e as problematizações suscitadas em relação à imagem fílmica são inexauríveis.

Ao pensarmos de maneira especial na experiência educativa, poderíamos afirmar que o desafio está em se deixar despojar de imagens fílmicas que assegurem um cenário conhecido, um roteiro fixo, um personagem que represente sempre o mesmo papel e se encaminhe para um final previsível. A coragem está em vislumbrar diferentes cenários e roteiros, mudar os scripts conforme as contingências de cada cena, oferecer espaços para a improvisação e ficcionar tantos finais quantos forem possíveis.

\section{O que aprendemos com essa experiência? Algumas possibilidades...}

Procuro despir-me do que aprendi,

Procuro esquecer-me do modo de lembrar que me ensinaram,

E raspar a tinta com que me pintaram os sentidos (...)

E assim escrevo, querendo sentir a Natureza, nem sequer como um homem,

Mas como quem sente a Natureza, e mais nada (PESSOA, 2006, p.

25).

Revista Digital do LAV - Santa Maria - vol. 10, n. 2, p. 39 - 55 - mai./ago. 2017 ISSN 1983 - 7348 http://dx.doi.org/10.5902/1983734828786 
Os dois encontros que tivemos com o filme 'A Árvore da Vida' (2011), tanto a experiência no cinema quanto na universidade com os acadêmicos, mostraram-nos que as sensações de incômodo e de dissonância preponderaram. Alguns não se sentiram nem um pouco afetados pelas imagens, negando-se a entrar em contato por não fazerem sentido para eles. Outros foram tocados de um modo singular e conseguiram estabelecer conexões para além do que parecia esperado.

Na experiência educativa não acontece o mesmo? Lançamos convites, possibilidades de encontros, aproximações com signos, mas não temos certeza de que esse endereçamento chegará a seu destinatário, que o convite será aceito e que as relações irão a acontecer. O pensar pode ou não acontecer, visto que depende das contingências de um encontro, das forças implicadas, do quanto nos deixamos violentar pelo impensado do pensamento.

É essa incerteza que nos impulsiona a seguir adiante na docência, é esse espaço desconhecido e desafiador que nos incita a apostar na educação. Gallo (2003, p. 103) sugere que é justamente aí que se reconhece "a beleza do processo educativo: agimos, sem nunca saber qual será o resultado de nossas ações". É quando percorremos um espaço não familiar que nos sentimos vivos, atuantes, pois não estamos apenas representando as cenas que ensaiamos e reproduzindo as falas que decoramos, mas estamos vivendo intensamente cada encontro.

Deixar-se contaminar pelas imagens inusitadas do percurso, pelas sensações que nos são oferecida, pelo que acontece no 'entre' do mundo, possibilita viver a cada dia de maneira renovada. Talvez essa seja uma oportunidade de 'desaprender' o que já se sabe, de desapegar de verdades fixas e limitadoras e se abrir ao que não se sabe, a algo que não está previsto. Essa abertura oportuniza a possibilidade das certezas se modificarem e nascerem diferentes do que eram, viabilizando que inusitados saberes possam vir ao mundo e que as experiências se diferenciem a cada vez.

Portar um olhar livre, desapegado e sem o compromisso de sempre reconhecer e interpretar talvez seja o nosso desafio maior. E, quiçá, com tudo isso possamos visualizar aquilo que não era visto ou, quem sabe, ver de outro modo o que era visualizado costumeiramente, instigando-nos a nos 'despir do que aprendemos', para, a partir disso, sermos capazes de inventar outras possibilidades de 'pintar' no mundo.

\section{Referencias}

BLANCHOT, Maurice. A parte do fogo [tradução de Ana Maria Scherer]. Rio de Janeiro: Rocco, 1997.

GALLO, Silvio. Deleuze \& a Educação. Belo Horizonte: Autêntica, 2003.

Revista Digital do LAV - Santa Maria - vol. 10, n. 2, p. 39 - 55 - mai./ago. 2017 ISSN 1983 - 7348 http://dx.doi.org/10.5902/1983734828786 
GILLES, Deleuze. Cinema 1 - A imagem-movimento. [tradução de Stella Senra]. São Paulo: Brasiliense, 1983.

. Cinema 2 - A imagem-tempo. [tradução de Eloisa de Araújo Ribeiro]. São

Paulo: Brasiliense, 1990.

. Proust e os Signos [tradução de Antônio Piquet e Roberto Machado]. 2. ed.

Rio de Janeiro: Forense Universitária, 2006a.

. Diferença e repetição [tradução de Luiz Orlandi e Roberto Machado]. 2. ed. Rio de Janeiro, 2006b.

A dobra: Leibniz e o barroco [tradução de Luiz Orlandi]. 4. ed. Campinas, S P: Papirus, 2007.

. Conversações [tradução de Peter Pál Pelbart]. 2. ed. São Paulo: Ed. 34, 2010.

PELBART, Peter Pál. O tempo não reconciliado. Imagens de tempo em Deleuze. São Paulo: Perspectiva, 2010.

PESSOA, Fernando. Obra poética II - poemas de Alberto Caeiro. Porto Alegre: L\&PM, 2006.

RANCIÈRE, Jacques. As distâncias do cinema [tradução de Estela dos Santos Abreu]. Rio de Janeiro: Contraponto, 2012.

OLIVEIRA, Marilda Oliveira de. O cinema como modo de pensamento, o cinema como forma de forçar a pensar. In: MARTINS, Raimundo; TOURINHO, Irene (Orgs.)

Pedagogias culturais. Santa Maria, Edufsm, 2014. p. 165-176.

VASCONCELLOS, Jorge. Deleuze e o Cinema. Rio de Janeiro: Editora Moderna Ltda, 2006.

ZABALZA, Miguel. Diários de aula: um instrumento de pesquisa e desenvolvimento profissional [tradução de Ernani Rosa]. Porto Alegre: Armed, 2004.

\section{Filmografia}

A ÁRVORE da Vida. Direção de Terrence Frederick Malick. Estados Unidos, 2011.

Disponível em: <https://www.youtube.com/watch?v=ITHQcWt5Tq0>. Acesso em: 28 jul., 2015.

\footnotetext{
i Pós-Doutoranda (2015-2017) junto ao Programa de Pós-Graduação em Educação (PPGAE), na Universidade Federal de Santa Maria. Doutora em Educação. Membro do GEPAEC/UFSM.

ii Doutora em História da Arte, credenciada no Programa de Pós-Graduação em Educação, Mestrado e Doutorado (PPGE/CE/UFSM), na Linha de Pesquisa LP4: Educação e Artes.
}

Revista Digital do LAV - Santa Maria - vol. 10, n. 2, p. 39 - 55 - mai./ago. 2017 ISSN 1983 - 7348 http://dx.doi.org/10.5902/1983734828786 
Coordenadora do GEPAEC - Grupo de Estudos e Pesquisas em Arte, Educação e Cultura da UFSM. Editora da Revista Digital do LAV.

Enviado em: 29 de junho de 2017.

Aprovado em: 13 de julho de 2017. 